УДК $551.5+553.9$

DOI 10.29222/ipng.2078-5712.2018-23.art19

\title{
SURFACE ATMOSPHERIC ELECTRICITY ELEMENTS AND GEOPHYSICS
}

\author{
Shuleikin V.N. \\ Oil and Gas Research Institute RAS \\ E-mail: shvn1947@yandex.ru
}

\begin{abstract}
A history of observations of thunderstorm electricity and good weather electricity is presented. Relationship between hydrogen, methane, radon, atmospheric electric field and polar conductivities of air are established. The prospects of using atmospheric-electrical observations in problems of applied geophysics are shown.
\end{abstract}

Keywords: hydrogen, methane, radon, atmospheric electric field, polar conductivities.

\section{ПРИЗЕМНОЕ АТМОСФЕРНОЕ ЭЛЕКТРИЧЕСТВО И ГЕОФИЗИКА}

\author{
Шулейкин В.Н. \\ Институт проблем нефти и газа РАН \\ E-mail: shvn1947@yandex.ru
}

Аннотация. Представлена история наблюдений за грозовым электричеством и электричеством хорошей погоды. Установлена взаимосвязь между водородом, метаном, радоном, атмосферным электрическим полем и полярной проводимостью воздуха. Показаны перспективы использования атмосферно-электрических наблюдений в задачах прикладной геофизики.

Ключевые слова: водород, метан, радон, атмосферное электрическое поле, полярные проводимости.

\section{Introduction}

Historically, almost at the same time in the mid-1800s, Benjamin Franklin, Mikhail Lomonosov, and Georg Richmann have started investigating the thunderstorm electricity. In 1750, B. Franklin has suggested an experiment that uses a kite flown to a thunderstorm cloud. On June 15 of the same year in Philadelphia, Benjamin Franklin has implemented his own experiment with a kite. He succeeded in extracting a spark from a wet whip-cord connected to a kite with a metal tip [1]. In 1760, B. Franklin has installed the first lightning conductor on West the tradesman house in Philadelphia.

In 1745, with the assistance of M. Lomonosov, the Academician Georg Richmann has developed an original design of the first electrical-type instrument, the "electric indicator". The 
"electric indicator" differed fundamentally from already known electroscope by a linen thread, instead of vanes, hung on to a vertical rod and deflected. This deflection was then measured by graduated wooden quadrant scale.

According to G. Richmann, this particular modernization allowed to measure "higher or lower electricity level". M. Lomonosov and G. Richmann used this "electric indicator" in the creation of a "thunder machine" - the first fixed installation for surveillance over the intensity of electric discharges in the atmosphere. This "electric indicator" was installed in a compartment, and its metal pile was connected by a wire to a metal rod on the roof. Using the "thunder machine", M.V. Lomonosov and G.W. Richmann showed that electricity was present in the atmosphere even when there was no thunderstorm - sometimes, the linen thread deflected from verticality under calm weather conditions [2]. They have presented a strong case that lightnings are powerful electrical discharges in the atmosphere.

Since the early 1800 s, the interest of researchers in thunderstorm electricity have slightly decreased. Attention was focused on the research of "good weather" electricity [3-5].

\section{Elements of surface atmospheric electricity and geophysics}

In the late $19^{\text {th }}$ century, at the Imperial Meteorological Observatory in Tokyo primary attempts to find relations between electrical perturbations of the atmosphere resulting from processes that take place in the Earth crust were undertaken. Analysis of the annual data array before and after seismic events in Japan has revealed the presence of anomalous variations in the atmospheric potential [6].

In the $20^{\text {th }}$ century, a few dozens of works illustrating anomalies of the atmospheric electric field (AEF) prior to seismic events [7-14]. In the 1980s, at the peak of interest in the predictive topics, these anomalies were attributed to short-term precursors $[15,16]$ and characterized by manifestation time of tens of minutes to hours before the earthquake, bipolarity, and amplitudes multifold exceeding the background level. Modern field data on AEF variations during the preparation of seismic events was mainly obtained in Kamchatka and China [17-22]. It expanded time for the occurrence of anomalous variations to a month and confirmed information on bipolarity and amplitude manifestations.

The space charge of the surface air owes its origin to ionization by exhaled soil radon [23-25]. In summer 1914, this effect was used in prospecting radioactive ores carried out by the Moscow Radium Expedition in Fergana, Uzbekistan [26]. In 1919, S. Kurbatov performed lab studies of the ionization radiation of rocks sampled from the Yulin mine near Minusinsk, 
Krasnoyarsk Krai, Russia. In 1920, using these lab results, he succeeded in finding a deposit of radioactive ores located $12-13 \mathrm{~km}$ southeast from the Yulin mine.

The molecular weight of radon is 222 that excludes a possibility of its separate subvertical migration. This means that among soil air gases its carriers to the subsurface soil layers and the surface atmosphere should be present.

As water-gas systems are lifting in the zones of increased rock permeability, volatile gases dissolved in water tend to separate into self-contained phases in the form of separate bubbles. In the course of the subvertical motion in the bubbles, a pressure drop occurs and volume - the contact area of the bubbles with the liquid and the rock - increases. Bubbles become natural degasifiers where, along with other gases, soil radon, which is formed in underground water-gas systems during the decay of dissolved radium salts, also drains [27, 28].

Bubbles carry the gaseous emanation to the surface atmosphere. At the ground surface, the exhaling soil radon acts as the sole atmospheric air ionizer [23, 24, 29]. Light ions produced by ionization determine the polar conductivity of the surface air; a combination of light ions with neutral condensation nuclei causes the formation of heavy ions generally responsible for the atmospheric electric field - AEF. According to estimates [23], ionization in the air layer at the altitude up to $0.5 \mathrm{~km}$ is by $75 \%$ caused by gamma radiation of the soil radon and by $25 \%$ by cosmic radiation; at the altitudes of 0.5 to $1.0 \mathrm{~km}$ the situation is different: $64 \%$ of air is ionized by space radiation and only $36 \%$ of air by the soil radon.

Traditionally, all volatile gases of the soil air were believed to be radon carriers to subsurface soil layers and the atmosphere [27, 28]. However, recent experiments have shown that the only two of these gases - methane and hydrogen - are radon carriers [30-32].

By way of illustration, let us analyze complex field observation data of the soil air radon and lab studies of soil air samples for hydrogen, methane, carbon dioxide, and nitrogen. The soil air was sampled in the area of the Kaluga Ring Structure and near Shchelkovo town with simultaneous recording of volumetric ground radon activity. Concentrations of nitrogen and carbon dioxide change in antiphase and manifest a rigorous correlation $k\left(\mathrm{~N}_{2} ; \mathrm{CO}_{2}\right)=(-0.99)$ in the absence of a correlation with methane and hydrogen $\left|k\left(\mathrm{H}_{2} ; \mathrm{CO}_{2}\right)\right|=0.28 ;\left|k\left(\mathrm{CH}_{4} ; \mathrm{CO}_{2}\right)\right|=$ 0.29 , respectively. The correlation coefficient of hydrogen and methane is very high $k\left(\mathrm{H}_{2} ; \mathrm{CH}_{4}\right)=0.96$; correlation coefficients between concentrations of these two volatile gases with volumetric radon activity are also quite high: $k\left(\mathrm{Rn} ; \mathrm{H}_{2}\right)=0.84, k\left(\mathrm{Rn} ; \mathrm{CH}_{4}\right)=0.89$. A slight decrease in the correlation coefficients of volatile gases with volumetric radon activity has a 
clear physical explanation - the accuracy of hydrogen and methane concentrations determined in the laboratory is much higher than that of field measurements of volumetric radon activity.

The result obtained can be clearly explained in terms of physics. Radon was airborne detected at kilometer range altitudes $[33,34]$. This means that bubbles of carrier gases in the ground should also "float" in the atmospheric air. For this purpose, their weight should be less than that of atmospheric air. This is true for hydrogen and methane and untrue for nitrogen and carbon dioxide.

Following the logic of this presentation, the pool of carrier gases for radon in the surface soil layers and the surface atmosphere should include all gases that have a lighter weight than the atmospheric air, helium and water vapors, in particular. However, helium, as well as radon, is among inert gases and, therefore, it should be excluded from the pool of carriers. A bubble of one inert gas is unable to capture a molecule of another inert gas. Water vapors will actively enter the atmosphere during evaporation from the Earth's surface, where the radon content is very low and comparable with the concentration of exhaled ionizer. On the one hand, the concentration of exhaled radon will increase, however, very slightly that will cause a slight decrease in AEF. On the other hand, water evaporation will sharply increase the density of neutral condensation nuclei that will cause a significant increase in AEF. The result of the simultaneous progress of these two processes will be discussed below with the electrode effect.

The presence of radon in the Earth's crust will be determined by the parent matter distribution. Table 1 shows data of the research by Academician V.I. Vernadsky Biogeochemical Laboratory on the distribution of radium in the Earth's biosphere.

As follows from Table 1, the radium content in soils is by only an order of magnitude lower than in the rock. In clay, in particular, which is an aquiclude of aquifers, the average radium content is $1.3 \times 10^{-10} \%$ that is only a half as much as in granites, $2.58 \times 10^{-10} \%$ [35].

Table 1

Radium content in the Earth's biosphere

\begin{tabular}{|l|c|}
\hline & Radium concentration, \% \\
\hline 1. Rocks & $10^{-9}-10^{-10}$ \\
\hline 2. Soils & $10^{-10}-10^{-11}$ \\
\hline 3. Vegetation & $10^{-12}$ \\
\hline 4. Animals & $10^{-13}$ \\
\hline 5. River and sea waters & $10^{-12}-10^{-14}$ \\
\hline
\end{tabular}


The Earth's surface carries a negative charge, which causes redistribution of the space charge of the surface atmosphere. At the surface, the negative charge concentration is zero and the positive charge concentration is maximal. According to recent calculations, depending on the ionization rate, temperature, and turbulence, volumetric charge concentrations can come to a quasi-stable level can occur at altitudes up to $10 \mathrm{~m}$. The region above which the volume concentrations of positive and negative charges reach close to background levels is defined as the electrode effect development zone.

Virtually all surface atmospheric electricity parameters are measured at heights of several decimeters to meters above the ground, i.e., by definition, in the zone of the electrode effect. Therefore, the reasons for recorded AEF variations should primarily be considered in terms of the influence of the electrode effect on field variations in the indicated range of altitudes.

Since the middle 1900s, the theory of the electrode effect has been developed [36-40]. Solutions came off only when light ions were present or when comparable concentrations of light and heavy ions were observed in the atmosphere. This in no way corresponds to the real atmospheric conditions. In the recent years, finally, a mathematical model of electrodynamic processes in the surface atmosphere was created under the conditions of the true presence of neutral condensation nuclei in it $[41,42]$. Solving a system of equations that describe this model has led to the terms of classical and reversible electrode effects.

In the case of the classical electrode effect, at neutral condensation nuclei concentrations of $\mathrm{N} \sim\left(10^{2}-10^{3}\right) \mathrm{cm}^{-3}$ and the ionization rate (the concentration of radon exhalation) of 7-9 decays per second, space charge of the surface air is generally provided by light ions. The atmospheric electric field created by the volumetric concentrations of positive and negative charges will come to the quasi-stable background level at altitudes of up to $10 \mathrm{~m}$. Table 2 shows the space charge density for light and heavy ions at altitudes of $0.5 \mathrm{~m}$ and $1.0 \mathrm{~m}$ above the ground for the case of the classical electrode effect.

Table 2

\section{Light and heavy ions charge density for the case of the classical electrode effect}

\begin{tabular}{|c|c|c|}
\hline Altitude, $\mathrm{m}$ & $\begin{array}{c}\text { Light ions space } \\
\text { charge density, } \\
{\left[\mathrm{pC} / \mathrm{m}^{3}\right]}\end{array}$ & $\begin{array}{c}\text { Heavy ions space } \\
\text { charge density, } \\
{\left[\mathrm{pC} / \mathrm{m}^{3}\right]}\end{array}$ \\
\hline 0.5 & $\sim(180-110)$ & $\sim(10-25)$ \\
\hline 1.0 & $\sim(25-10)$ & $\sim(0-20)$ \\
\hline
\end{tabular}


For neutral condensation nuclei concentrations of $\mathrm{N} \sim 5 \times 10^{3} \mathrm{~cm}^{-3}-10^{4} \mathrm{~cm}^{-3}$, a reversible electrode effect takes place. A negative space charge layer where AEF falls below the quasistable background level and comes to it already after the inflection will form above the ground. The ionization rate increase will strengthen the effect.

The result obtained indicates that formation of heavy ions strongly depends on neutral condensation nuclei concentrations. Concentrations of about $\left(10^{2}-10^{3}\right) \mathrm{cm}^{-3}$ inherent to the environmentally clean atmosphere, cause the classical electrode effect, whereas concentrations of $5 \times 10^{3} \mathrm{~cm}^{-3}$ or higher that can be observed in urban agglomerations and industrial zones, cause the reversible electrode effect.

In these examples of electrode effect calculations, the electric interaction of charges was only considered. Turbulence "dilutes" the surface space charge thereby broadening the electrode effect manifestation zone - the turbulent electrode effect.

Generally speaking, turbulence is not an additional space charge generator at the ground surface. However, as the wind speed and, consequently, turbulent mixing speed increases, soil radon influx will occur $[41,42]$. In turn, an increase in surface air ionization will cause an increase in the space charge density at the ground surface. This phenomenon is of only interest from a physics perspective of the electrode effect in case of developed turbulence. All observations of variations in surface atmospheric electricity elements above geological heterogeneities and zones of geodynamic processes should be carried out at wind speeds up to $3 \mathrm{~m} / \mathrm{s}$.

\section{The hydrogen, methane, radon, atmospheric electric field and polar conductivities of air}

The data obtained allow for developing a model of hydrogen-methane-radon and atmospheric-electrical bonding. The subvertical hydrogen and methane flow captures radon at a depth of 4-6 meters and lifts it to subsurface soil layers and the surface atmosphere. Light ions formed thereat determine polar conductivities; their recombination with neutral condensation nuclei sets AEF, see Fig. 1.

Radon concentration in the soil is, at least, by 2 orders of magnitude higher than in the atmosphere [43, 44]. This means that the 2-fold change in ionizer efflux to the atmosphere will not affect radon content in the soil. However, in the surface atmosphere, such changes will lead to a two-fold change in the exhaled radon concentration: to a two-fold change in polar conductivities and the field. To put it differently, the surface atmospheric electricity elements 
will be extremely sensitive to changes in subvertical flows density of carrier gases - hydrogen and methane.

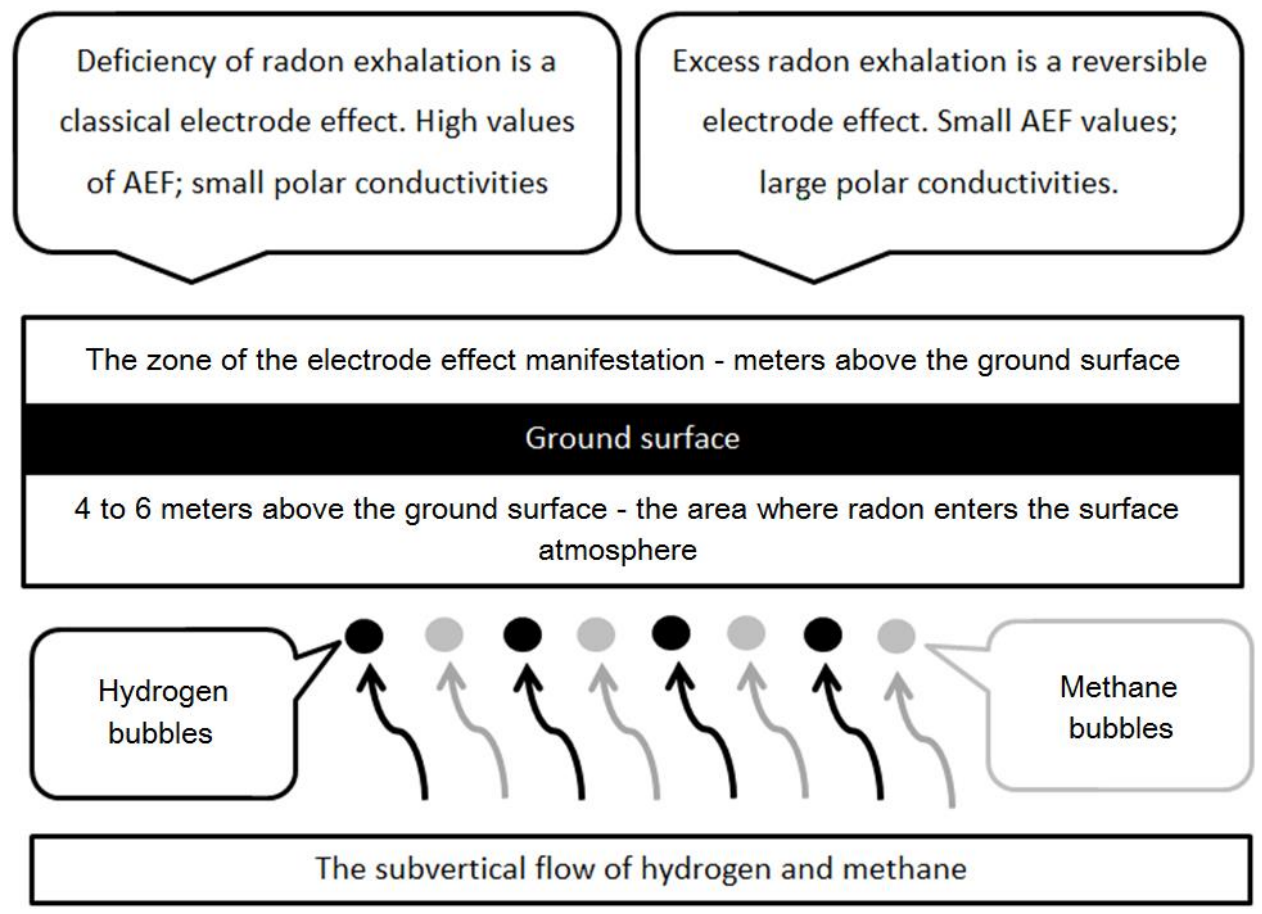

Fig. 1. Model representation of relations between hydrogen, methane, radon and surface atmospheric electricity elements

At the last stage of analysis of relations between methane, radon, hydrogen, and surface atmospheric electricity parameters, let us consider one more experimental fact. A data bank of 72 pairs of values on hydrogen and methane content in the subsurface soil layers of the soil was formed during long-term observations at the Kaluga Ring Structure and near Shchelkovo, Stavropol and Nevinnomyssk. Let us analyze relations of these two volatile gases in the range of methane concentration of $10^{-6}$ to $10^{-2}$ vol.\% [30, 45, 46].

The correlation coefficient $k\left(\mathrm{CH}_{4}, \mathrm{H}_{2}\right)_{72}=0.76$ is quite high. However, in the case of logarithms $\ln \left(\mathrm{H}_{2}\right)$ and $\ln \left(\mathrm{CH}_{4}\right)$ the correlation coefficient between them increases to $k\left[\mathrm{Ln}\left(\mathrm{H}_{2}\right)\right.$, $\left.\operatorname{Ln}\left(\mathrm{CH}_{4}\right)\right]=0.96$. Linear approximation allows to introduce, with the confidence $D=0.92$, an equation of constrains for studied parameters:

$$
\mathrm{CH}_{4}=15.83 \exp \left[1.675 \ln \left(\mathrm{H}_{2}\right)\right],[\operatorname{vol} . \%],
$$

where hydrogen concentration is normalized by 1 vol.\%. Fig. 2. shows plots of measured and calculated methane content in the soil by 72 point data sets.

Taking into account the range of methane concentration gradients, which is 5 orders of magnitude $\left[\left(10^{-6}-10^{-2}\right)\right.$ vol.\%], the coincidence of measured and calculated values may be 
considered ideal. Here it should be borne in mind that the soil air was sampled by different operators in different years and analyzed on different laboratory equipment.

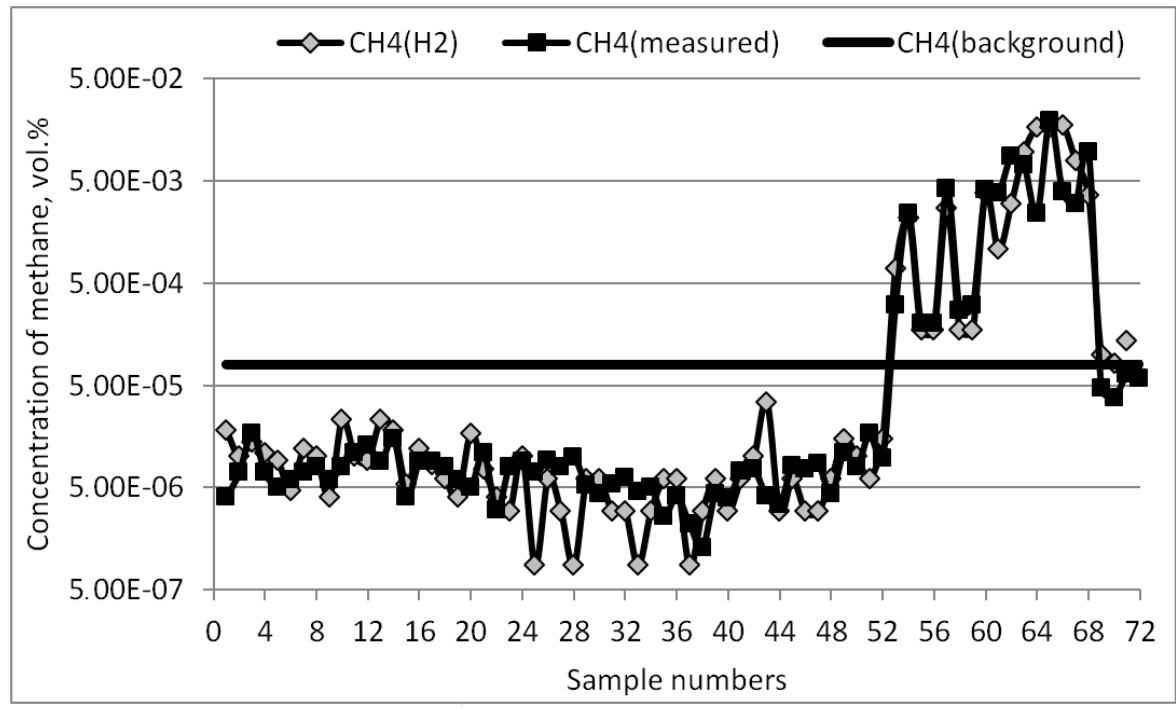

Fig. 2. Calculated and measured values of methane content in the soil. Straight line shows the average background level of methane in the soil

The exponential relation obtained between methane and hydrogen is clear. In a quasistable state, distribution of deep subvertical gas flow in the geological environment, as it approaches the daylight surface, will be described by a "barometric formula", where the exponent also includes the gas density.

At low concentrations and their insignificant changes as in 52 samples taken near Stavropol, the exponent can be confidently approximated by a linear relationship. The correlation coefficient of calculated soil methane contents obtained from the above expression and at linear approximation is very high $-k\left\{\mathrm{CH}_{4}\left[\exp \left(\mathrm{H}_{2}\right)\right], \mathrm{CH}_{4}\left(\mathrm{H}_{2}\right)\right\}=0.98$.

Hydrogen, methane, radon, atmospheric electric field and polar air conductance values are amenable to express measurements $[30,45,46]$. This means that within the framework of the introduced model representation of the relations between gas and electrical characteristics of the ground and atmosphere and the measurement data of these parameters, recalculation of soil methane is possible.

\section{Conclusion}

Measurements of surface atmospheric electricity elements in conjunction with hydrogen and radon have never and nowhere been used in addressing tasks of applied geophysics. Numerous field observations described clearly illustrate the prospects of use in monitoring of fault zones, oil and gas fields, ore bodies, aquifer dynamics, and monitoring of landslide stresses. 
Essentially, a new area of research for the interaction of fields of different origin under specific geological and geodynamic conditions was established. The outlined materials expands the physical interpretation of the nature of surface atmospheric electricity and is of obvious interest for addressing applied geophysics problems.

Статья написана в рамках выполнения государственного задания (тема «Энергетика, динамика и дегазация Земли, теоретические и экспериментальные основы инновачионных сейсмоакустических технологий исследования геологической среды и контроля за объектами нефтегазодобычи», № AAAA-A16-116021510125-7).

\section{REFERENCES}

1. Priestley J. The history and present state of electricity with original experiments. London: Printed for J. Dodsley, J. Johnson and T. Gadell, 1767. 700 p.

2. St. Petersburg vedomosti. 1753. № 45.

3. Gerasimenko V.I. Electrical and meteorological fields lower troposphere // L.: Gidrometizdat. In the book Atmospheric electricity. 1976. P. 25-31.

4. Guide on land-based observations of atmospheric electricity elements. L.: Izd. MGO A.I. Voyeykova. 1960.95 p.

5. Semenov K.A. Good weather and atmospheric electricity elements // Proceedings MGO A.I. Voyeykova. 1982. Iss. 455. P. 112-119.

6. Milne J. Earthquakes in connection with electric and magnetic phenomena // Trans. Seismol. Soc. Jap. 1890. Vol. 15. P. 135-164.

7. Bonchkovskij V.F. Earthquakes and methods of their study. M.: Izd. SA of the USSR. 1949. $88 \mathrm{p}$.

8. Bonchkovskij V.F. Measuring electrical potential gradient in the atmosphere, as one possible foreshock // Proceedings of the Geophysical Institute. 1954. No. 25(125). P. 192-206.

9. Cherniavsky E.A. Electric storm // SAGU Bulletin. 1925. No. 10. P. 157-162.

10. Cherniavsky E.A. Atmospheric-electrical and electrotelluric phenomena in the course of earthquakes // Sotsialisticheskaya Nauka i Tekhnika. 1935. No. 12. P. 26-35.

11. Cherniavsky E.A. Atmospheric-electrical harbingers of earthquakes // Meteorology and hydrology in Uzbekistan. Tashkent: Izd. Akad. Nauk Uzb. SSR. 1955. P. 317-327.

12. Sidorin A.Ya. About perturbations of electric potential gradient of gharm test range atmosphere in 1949-50 // Electrical Interactions of Geosphere Shells. M.: Publ. IPE RAS. 2000. P. 148-165. 
13. Sidorin A.Ya. Perturbations of atmospheric electric potential and earthquakes at Garm test range // Seismic Instruments. 2000. Vol. 33. P. 78-95.

14. Cerfas K.E. Atmospheric electricity phenomena preceding an earthquake // The Earthquake in Tashkent on 26.06.66. Tashkent: FAN, 1971. P. 184-187.

15. Electromagnetic precursors of earthquakes. M.: Nauka. Collection edited by Academician M.A. Sadovsky. 1982. 88 p.

16. Search electromagnetic foreshock. M.: Publ. IPE AS USSR. Collection edited By Prof. M.B. Gokhberg. 1988. 243 p.

17. Rulenko O.P., Ivanov A.V., Shumeiko A.V. Short-term atmospheric-electric precursor of the Kamchatka earthquake on 6.III.1992, M=6.1 // Doklady RAN. 1992. Vol. 326, No. 6. P. 980-982.

18. Rulenko O.P., Wives G.I., Vershinin E.F. Measurements of atmospheric electric field and natural electromagnetic radiation prior to the Kamchatka earthquake on 13.11.1993, M=7.0 // Doklady RAN. 1996. Vol. 348, No. 6. P. 814-816.

19. Hao J.G. Near earth surface anomalies of the atmospheric field and earthquake // Acts Seismol. Sin. 1988. Vol. 1, No. 2. P. 48-54.

20. Hao J.G., Pan H.W., Li D.R. Regional features of atmospheric electric field anomalies before earthquakes // Earthquake. 1993. No. 6. P. 48-54.

21. Hao J.G., Zhang Y.F., Li D.R., Tang T.M., Liu X.Q. Ultra low frequency electromagnetic wave anomaly and its spectrum characteristics before earthquakes // Acts Seismol. Sin. 1995. Vol. 8, No. 1. P. 101-109.

22. Hao J.G., Tang T.M., Liu X.Q. A rind of information on short-term and imminent earthquake precursors research on atmospheric electric field anomalies before earthquakes // Acts Seismol. Sin. 1998. Vol. 11, No. 1. P. 121-131.

23. Tverskoi P.N. The Course of meteorology. L.: Gidrometizdat. 1951.887 p.

24. Frankel Ya.I. Theory of atmospheric electricity phenomena. L.: GITTA. 1949. 155 p.

25. Baranov V.I. Radiometry. M.: Izd. AN SSSR. 1956. 343 p.

26. Shcherbakov D. Finds deposits of radioactive minerals special methods of searching // Nature. 1923. No. 7-12. P. 97-100.

27. Voitov G.I., Gusev A.S., Shuleikin V.N. et al. Emanation (hydrogen-radon) and electric effects above complex tectonic structures (on the example of Alexandrovskaya zone of pre-fault elevations, Belarus) // DAN RAN. 2000. Vol. 370, No. 1. P. 105-108. 
28. Gergedava Sh.K., Buzinov S.N., Shuleikin V.N., Rudakov V.P., Voitov G.I. Unconventional geophysics for underground gas storage facilities // Oil, Gas and Business. 2001. No. 5(43). P. 2-7.

29. Imyanitov I.M., Chubarinov E.V. Free atmosphere electricity. L.: Gidrometeoizdat. 1965. $240 \mathrm{p}$.

30. Zubarev A.P., Shuleikin V.N. Complex geophysical and geochemical monitoring for underground gas storage facility operation. M.: Izd. Gasprom UGS OOO. 2009. 264 p.

31. Shuleikin V.N. Indirect monitoring of methane concentration above hydrocarbon accumulations - technique and metrology // GEON Proceedings of International Conference «Fundamental Problems of Oil and Gas Bearing Hydrology». M., 2005. P. 551-555.

32. Shuleikin V.N. Atmospheric electricity and physics of the earth. M.: Izd. FED+. 2006. $159 \mathrm{p}$.

33. Voitov G.I. Chemistry and scope of the modern natural gas flow in various geostructural zones of the earth // Zhurnal Vses. Khim. Obsch. im. D.I. Mendeleeva. 1986. Vol. XXXI, No. 5. P. 533-540.

34. Voitov G.I., Starobinets I.S., Usmanov R.I. About density of $\mathrm{CH}_{4}$ flows to the atmosphere in oil and gas Bearing regions (on the example of Amu-Darya basin) // DAN SSSR. 1990. Vol. 1313, No. 6. P. 1444-1448.

35. Koshkin N., Shirkevich M. Handbook of elementary physics. M.: Nauka. 1976. 255 p.

36. Chalmers J.A. The theory of the electrode effect I // J. Atm. and Terr. Phys. 1966. Vol. 28. P. 565-572.

37. Chalmers J.A. The theory of the electrode effect II // J. Atm. and Terr. Phys. 1966. Vol. 28. P. 573-579.

38. Chalmers J.A. The theory of the electrode effect III // J. Atm. and Terr. Phys. 1966. Vol. 28. P. 1029-1033.

39. Chalmers J.A. The theory of the electrode effect IV // J. Atm. and Terr. Phys. 1967. Vol. 29. P. 217-219.

40. Crozier W.D. Atmospheric electrical profiles below three meters // J. Geophys. Res. 1965. Vol. 70, No. 20. P. 2785-2790.

41. Redin A.A. Mathematical modeling of electrodynamic processes in the surface layer in conditions of airborne contamination: Candidate Thesis. Taganrog. 2011. 19 p. 
42. Redin A.A., Kupovykh G.V., Boldyrev A.S. Electrodynamic model of turbulent nearsurface layer in the presence of multiply charged aerosol particles // VII All-Russian Conference on Atmospheric Electricity. SPb., 2012. P. 199-201.

43. Sisigina T.I. Measurements of radon exhalation from the rock surface // Problems of Nuclear Meteorology. M.: Gosatomizdat. 1962. P. 104-111.

44. Sisigina T.I. Radon exhalation from the surface of soils of several types in European part of the USSR and Kazakhstan // Radioactive Isotopes in the Atmosphere and Their Use in Meteorology. M.: Atomizdat. 1965. P. 40-48.

45. Shulejkin V.N., Schukin G.G., Kupovyh G.V. Development methods and tools applied geophysics - atmospheric-electrical monitoring geological heterogeneity and geodynamic processes zones. SPb.: Izd. RGGMU, 2015. 205 p.

46. Shuleikin V.N. Earth and atmospheric electricity. New York: Nova science publishers, 2018. 143 p. 